\title{
Correction to: Toward a phylogeny and biogeography of Diaphanosoma (Crustacea: Cladocera)
}

\author{
Henri J. Dumont • Bo-Ping Han 1 - Fei Fei Guo • Hua Chen • Dan Cheng • \\ Ping Liu • Lei Xu • La-Orsri Sanoamuang • Arnola C. Rietzler • \\ Shaolin Xu Andy Vierstraete $\cdot$ Manuel Elias-Gutierrez
}

Published online: 19 June 2021

(C) Springer Nature B.V. 2021

\section{Correction to: Aquat Ecol}

https://doi.org/10.1007/s10452-020-09819-0

The original publication of the article includes an error in the Abstract. The sentence: "The entire group shows (macro)morphological stasis in the presence of molecular evolution but Neodiaphanosoma is evolving at a much faster rate than Diaphanosoma s.s. that is either a younger group." should be read as: "The entire group shows (macro)morphological stasis in the presence of molecular evolution, but Diaphanosoma s.s. is either a younger group, or Neodiaphanosoma is evolving at a much faster rate than Diaphanosoma s.s.”.

Publisher's Note Springer Nature remains neutral with regard to jurisdictional claims in published maps and institutional affiliations.
The original article can be found online at https://doi.org/10.1007/s10452-020-09819-0.

H. J. Dumont · A. Vierstraete

Department of Biology, Ghent University, 9000 LedeganckstraatGent, Belgium

H. J. Dumont · B.-P. Han ( $\varangle)$.

F. F. Guo - H. Chen - D. Cheng - P. Liu - L. Xu - S. Xu

Department of Ecology and Hydrobiology, Jinan

University, Guangzhou 510632, China

e-mail: tbphan@jnu.edu.cn; tbphan@126.com

L.-O. Sanoamuang

Khon Kaen University, Khon Kaen 400002, Thailand

A. C. Rietzler

Department of General Biology, Federal University of

Minas Gerais, Belo Horizonte, Brazil

M. Elias-Gutierrez

El Colegio de la Frontera Sur, Chetumal, Mexico 